\title{
Pseudo-public political speech: Democratic implications of the Cambridge Analytica scandal
}

\author{
Jonathan Heawood \\ Chief Executive Officer, IMPRESS \\ E-mail: jonathan@impress.press
}

\section{Introduction}

On 29 July 2018, the House of Commons Select Committee on Digital, Culture, Media and Sport published a report on 'fake news' (DCMS, 2018). Oddly, but perhaps appropriately, the report wasn't actually about fake news. The Select Committee explained that, although they had begun by looking at fake news, they had been diverted by a series of stories about a company called Cambridge Analytica ${ }^{1}$ that were published in the Observer earlier this year.

In those articles, Carole Cadwalladr, ${ }^{2}$ the Observer journalist, had revealed that Cambridge Analytica, or companies linked to Cambridge Analytica, had used the personal data of about 200,000 Facebook users to build up detailed psychological profiles of up to 87 million Facebook users. Whilst the initial 200,000 users had voluntarily completed a personality test, they had not necessarily known how their answers would be used, and the 87 million users who were profiled had most certainly not given their informed consent for this (Cadwalladr, 2018). Cambridge Analytica used this massive database to help political campaigners in the United Kingdom, the United States and other countries to target Facebook users with highly specific messages.

This 'microtargeting' has been defined as 'a type of personalised communication that involves collecting information about people, and using that information to show them targeted political advertisements' (Borgesius et al., 2018: 81). Cambridge Analytica used a profiling tool called OCEAN to categorise Facebook users on the basis of their 'Openness', 'Conscientiousness', 'Extraversion', 'Agreeableness' and 'Neuroticism'. They then helped their clients to target users with the most effective messages. The Select Committee observed that Cambridge Analytica 'might play on the fears of someone who could be frightened into believing that they needed the right to have a gun to protect their home from intruders'

\footnotetext{
${ }^{1}$ URL: https://cambridgeanalytica.org.

${ }^{2}$ In June 2018, Carole Cadwalladr won the Orwell journalism prize, for her investigative work into Cambridge Analytica, URL: https://www.orwellfoundation.com/journalist/carole-cadwalladr/.
} 
(DCMS, 2018: 28). In their report, the Committee concluded that this 'relentless targeting of hyperpartisan views, which play to the fears and the prejudices of people, in order to alter their voting plans', is arguably 'more invasive than obviously false information'. They described the combined impact of fake news and microtargeting as a 'democratic crisis' (DCMS, 2018: 3).

It seems that we have a major problem on our hands. But what exactly is the problem? What is it about microtargeting that feeds into this 'democratic crisis'? And is this really a crisis, or simply another aspect of the moral panic that seems to be gripping us, as we make the transition from the analogue to the digital age? In this opinion piece, I ask whether - and, if so, how - microtargeting harms democracy. I suggest that part of the problem with microtargeted political advertisements is that they blur the distinction between forms of discourse that were once public, such as billboard posters and party-political broadcasts, and forms that were once 'private', such as letters and emails. Microtargeted political adverts are, in this respect, a 'pseudo-public' form of discourse. I then go on to ask why that should be a problem? Why should it matter whether a political communication is made in public or private? Why should it matter if we read a private message as if it were a public message? The standard answer is that, in private, our defences are lower than they are in public and we are therefore more vulnerable to being 'manipulated' or 'exploited'. This is what leads to the 'democratic crisis'. But why is this the case? It is not as if we have any great reason to trust political communications that are made in public. They are just as likely to be prone to misinformation, false claims and false promises as private communications. In fact, the cornerstone of our belief in the public sphere is that the public sphere can and should accommodate misinformation, false claims and false promises. So, the differences between public and private political communications are less than they at first appear. They are differences of degree, rather than fundamental differences of kind. As a result, if we want to address the current 'democratic crisis', then we need to attend not just to the new private sphere that has been facilitated by digital technology, but also to the challenges posed by the old public sphere that was facilitated by analogue technology, including communications that are made via the news media.

\section{The history of microtargeting}

The technique of microtargeting did not emerge fully-formed with the birth of the internet, although it undoubtedly thrives on the internet. Once upon a time, goods and services were advertised in the same way to all consumers. This was inefficient and ineffective. Not all consumers were interested in all products and some consumers were particularly interested in some products. Either way, there was wastage. So, advertisers developed ways of profiling consumers; working out where those consumers were to be found; and then targeting them. The mass media were vital to this process. Different newspapers, magazines, TV shows and radio stations cultivated different audiences, which media companies could then 'sell' to advertisers. In order to make the most of their position in the market, media companies tried to find out as much as possible about their audiences, through surveys and focus groups. Advertisers could then target a particular product at a particular audience in a particular way; or target the same product at different audiences in different ways. Either way, they stood a better chance of selling their wares. The classic example of this is soap powder, where essentially the same product was packaged up under different brands and marketed to different audiences in different ways, often through the sponsorship of long-running and engaging TV dramas, or soap operas.

This happy business model was disrupted by the arrival of digital media. New media companies can track consumers around the internet. They can follow not only our buying habits, but also our political preferences and sexual tastes. They can build up a highly sophisticated profile of each of us, drawing 
on hundreds or thousands of 'data points'. Social media platforms could not have been designed more beautifully for this purpose. They don't even need to pay us to take part in focus groups. We give them vast amounts of data, which they then sell to advertisers, including political advertisers. Advertisements on social media can target audiences at a granular level. A soap opera might have reached an audience of five million. A magazine advert might have reached an audience of fifty thousand. An advert on social media might reach an audience of fifty. It might, in theory, reach an audience of one. Microtargeting is not a side-effect of the new media economy, it is the driver of that economy. This is why personal data is often called the 'oil' of the new media economy.

\section{The harm of microtargeting}

Where's the harm in microtargeting and how does it threaten democracy? What is it about microtargeting that causes so much anxiety? The concerns that have been raised about microtargeting seem to boil down to the following six charges.

The first charge is that microtargeting is harmful because it exploits personal data. The audience member, or data subject, has not consented to her data being processed in this way. In the past, political campaigners might knock on your door. You might choose to open the door or not, and you might choose whether to listen to what they had to say. Now, the campaigners are already in your house. They know what's in your drawers and on your bookshelves and, to some extent, what's in your mind. You have been psychologically profiled and they are exploiting their knowledge of you to sell you their product. Some people might be happy to share their data for this purpose and others might not. So the issue here is one of consent, rather than one of profiling as such.

The second charge is that microtargeting is harmful because it conceals its true nature. A microtargeted political advert on Facebook might not announce itself as a political advert. Therefore, when the average Facebook user encounters that advert, she has her defences down and receives the message with the same lack of guile that she receives a letter or email from her mother-in-law or her best friend. She is outraged or energised or depressed by the message and acts accordingly - just as the advertiser intended.

The third charge is that microtargeting is harmful because claims made in private can't be corrected in the marketplace of ideas. For instance, a party might tell potential voters that it will take the UK out of the European Union without losing any of the benefits of EU membership. In the 'marketplace of ideas', the merits of this claim might be debated. In the darkness of social media, they may stand unchallenged.

A fourth and related charge is that microtargeting is harmful because it may contain misinformation. For instance, a party might simply tell lies. It might say that the UK makes a net contribution of $£ 350$ million to the EU budget every week. Again, this false claim cannot be put right and, again, voters are easily manipulated.

The fifth charge is that microtargeting is harmful because it allows political parties to make incompatible promises to different segments of the electorate. A party might, for instance, tell one set of voters that, after the election, annual increases in net-immigration will be eradicated. It might tell another set of voters that shortages of skilled labour will be met by an increase in foreign workers. These incompatible promises clearly cannot both be fulfilled and, as a result, a party might lack a clear mandate if it were elected to government.

The sixth charge is that microtargeting allows political actors outside our own country to target us with misinformation or disinformation. Thus, the Russian Internet Research Agency ${ }^{3}$ can use Facebook

\footnotetext{
${ }^{3}$ URL: https://en.wikipedia.org/wiki/Internet_Research_Agency.
} 
to build support for particular politicians in the UK or the US; or simply to spread confusion and discord by setting rival groups against each other.

\section{Democratic harm}

Taken together, these six charges suggest that the harm of microtargeting is that it trades on our expectations of public communications to smuggle through private messages. Seen in this light, microtargeting constitutes a 'pseudo-public' form of communication. This analysis suggests that all would be well if only these private messages could be hauled back into the light of day, where they could be exposed and challenged. For example, some commentators have concluded that the 'democratic crisis' would be alleviated if all microtargeted messages were published in a public database, so that we could all see what political parties were telling us in private. Borgesius at al. take this view. Although there is some logic in their position there are also some fundamental limitations. An extended passage from their paper illustrates the problem:

'A [...] threat for the public sphere is the fragmentation of the marketplace of ideas. A masscommunicated political campaign is organised around a small number of issues - for example health care, terrorism, and the economy. The majority of the electorate is aware of the stances of political parties with regard to these issues. An informed public allows political parties to engage in public debates, which can lead to deliberative processes. Voters can also become part of the deliberative process by engaging in the debates. However, if citizens lose interest in these overarching issues and focus on the issues that are more relevant to them, these public debates become less democratic and deliberative processes are cut short' (Borgesius et al., 2018: 89).

This account of microtargeting rests on a distinction between an 'old' or 'analogue' sphere of mass public communication and a 'new' or 'digital' sphere of private communication, where individuals are targeted with highly personalised messages. In this account, the old public sphere was more-or-less good and the new private sphere is more-or-less bad, and the fundamental problem of microtargeting is that it takes place in private.

\section{The limitations of the public sphere}

I believe that this implicit distinction between a 'good' old public sphere and a 'bad' new digital sphere is a bit of a fantasy. Where was this informed public in the public sphere? Where were these opportunities for deliberation? The previously mentioned examples, of the Brexit bus and the promises of Leave campaigners, could not have been made any more publicly. These claims were challenged in the public sphere but they were no less effective for that. In the analogue public sphere, the public was informed by the mass media and most deliberative processes were also a function of the mass media: televised debates, radio phone-ins, letters to the editor. Of course, there were also - and there still are town hall meetings and other forums outside the direct control of the mass media. However, it was only thanks to the mass media that political parties could communicate with large numbers of voters. Thus, a significant part of the information-sharing and deliberative functions of the analogue public sphere were conducted through media institutions that were no more innocent, and no more geared towards the interests of democracy, than the social media companies that now play host to political communications in the form of microtargeting. The public sphere did not prevent personal data from being exploited 
for purposes of advertising or propaganda. In fact, as I suggested earlier, the public sphere relied upon the exploitation of personal data. This was how media companies generated returns for their owners and shareholders: by capturing audiences with particular demographic or ideological characteristics and then selling those audiences to advertisers. The difference between the analogue public sphere and the digital private sphere in this respect is a difference of degree, not a difference of kind.

Similarly, the analogue public sphere allowed communications to mask their true nature. In newspapers, in particular, there is considerable scope to conceal the true nature of messages. A piece of content that appears to be journalism might in fact be closer to advertising or political propaganda. Whilst advertisers are bound by the UK Advertising Codes ${ }^{4}$ to identify advertisements as such, these regulations do not bite directly on newspaper publishers, whether they operate in print or online. And it is clear that some publications are keen to blur the distinction between editorial and advertising content, for instance with so-called 'advertising features', where content that looks like journalism has in fact been paid for and is controlled by the advertiser. News media companies can charge advertisers more for such features, on the very basis that consumers are more likely to engage trustingly with material that does not look like an advertisement. Furthermore, newspapers, both in print or online, are quite free to run highly opinionated political content. There is no legal requirement for this content to be based on accurate information. Newspapers that belong to the Independent Press Standards Organisation (IPSO), ${ }^{5}$ such as the Mail and the Sun, have on several occasions been allowed to publish inaccurate or distorted information on the grounds of 'freedom of expression'. IMPRESS,${ }^{6}$ has taken a rather more stringent view of articles published by publications such as the Canary $^{7}$ and $S k w a w k b o x,{ }^{8}$ where opinions were being presented as facts; or the facts were simply wrong. However, IMPRESS has no legal powers at its disposal, as press regulation in this country is purely voluntary. So, the public is just as exposed to misinformation, false promises and false claims in the public spaces of print and digital news media and political advertising as it is in the private spaces of social media. As a result, it is hard to sustain the idea that the problem with microtargeting is simply that it is a 'pseudo-public' form of discourse.

\section{Conclusion}

In conclusion, microtargeting is clearly a problem. It is a problem because it exploits personal data without informed consent; because it allows for the sharing of misinformation; and because it blurs the boundary between advertising and other forms of content. However, these problems are not unique to the digital sphere. The analogue public sphere is subject to the same pressures as the digital sphere. Old media companies, given half a chance, would probably behave much the same as new media companies. Their underlying business models are much the same, and therefore so are their motivations. Perhaps the most important difference between the analogue public sphere and the digital sphere is simply that we are accustomed to the old public sphere. We think that we are safe here because the landscape is so familiar. We simply do not see the dangers in this landscape. We do not see the 'crisis in democracy' that may in fact be endemic to this landscape.

\footnotetext{
${ }^{4}$ URL: https://www.asa.org.uk/codes-and-rulings/advertising-codes.html.

${ }^{5}$ URL: https://www.ipso.co.uk/.

${ }^{6}$ URL: https://www.impress.press.

${ }^{7}$ URL: https://www.thecanary.co.

${ }^{8}$ URL: https://skwawkbox.org.
} 
This can be highlighted via a thought experiment. Let us imagine that the digital sphere came first, and that the analogue public sphere only burst onto the scene in the last ten or fifteen years. Imagine the excitement and the outrage! Television channels broadcasting a non-stop diet of news, drama, sport and entertainment all mixed up! How could we as viewers possibly navigate our way through this maze? Newspapers that can make or break political parties without having to declare themselves as political organisations? What an extraordinary opportunity for manipulation! Radio sets that beam words and music into our ears at all hours of day and night - even when we are alone, and therefore at our most vulnerable. The horror! The moral panic would be at least as great as the current panic over new media, if not greater.

This is not a wholly frivolous point. There is value in familiarity. Just as we can more safely cross the road if we know how cars are likely to behave, so we can more safely navigate the public sphere if we're familiar with it. However, familiarity also blinds us to the dysfunctional aspects of the analogue public sphere, and these are just as significant as the dysfunctional aspects of the digital sphere. If we are serious about supporting democracy for the future, then we should be serious about addressing the old challenges that have been with us for so many years, just as much as the new challenges that are a function of the ongoing digital revolution.

\section{Endnote}

IMPRESS is a regulator designed for the future of media, building on the core principles of the past while innovating to deal with the challenges of a digital age. IMPRESS aims to ensure that quality independent journalism flourishes now and in the future. IMPRESS URL: https://www.impress.press/.

\section{References}

Cadwalladr, C. (2018) The Cambridge Analytica Files. The Guardian. Available at URL: https://www.theguardian.com/news/ series/cambridge-analytica-files.

Frederik, J., Zuiderveen Borgesius, F.J.Z., Möller, J., Kruikemeier, S., Fathaigh, Ó.R., Irion, K., Dobber, T., Bodo, B., de Vreese, C. (2018) Online political microtargeting: Promises and threats for democracy. Utrecht Law Review, 14(1), 82-96.

(DCMS) House of Commons Digital, Culture, Media and Sport Committee (UK). (2018) Disinformation and fake news: Interim Report. Fifth report of Session 2017-19, 28 July 2018, HC363. Available at URL: https://publications.parliament. $\mathrm{uk} / \mathrm{pa} / \mathrm{cm} 201719 / \mathrm{cmselect} / \mathrm{cmcumeds} / 363 / 36302 . \mathrm{htm}$. 